Portland State University

PDXScholar

1-30-1995

\title{
Methods of Language Assessment: A Survey of Oregon Public School Speech-language Pathologists
}

Staci Lee Johnson Ball

Portland State University

Follow this and additional works at: https://pdxscholar.library.pdx.edu/open_access_etds

Part of the Speech and Rhetorical Studies Commons

Let us know how access to this document benefits you.

\section{Recommended Citation}

Ball, Staci Lee Johnson, "Methods of Language Assessment: A Survey of Oregon Public School Speechlanguage Pathologists" (1995). Dissertations and Theses. Paper 4970.

https://doi.org/10.15760/etd.6846

This Thesis is brought to you for free and open access. It has been accepted for inclusion in Dissertations and Theses by an authorized administrator of PDXScholar. Please contact us if we can make this document more accessible: pdxscholar@pdx.edu. 
THESIS APPROVAL

The abstract and thesis of Staci Lee Johnson Ball for the Master of Science in Speech Communications: Speech and Hearing Sciences were presented January 30,1995 , and accepted by the thesis committee and the department. COMMITTEE APPROVALS: Joan McMahon, Chair
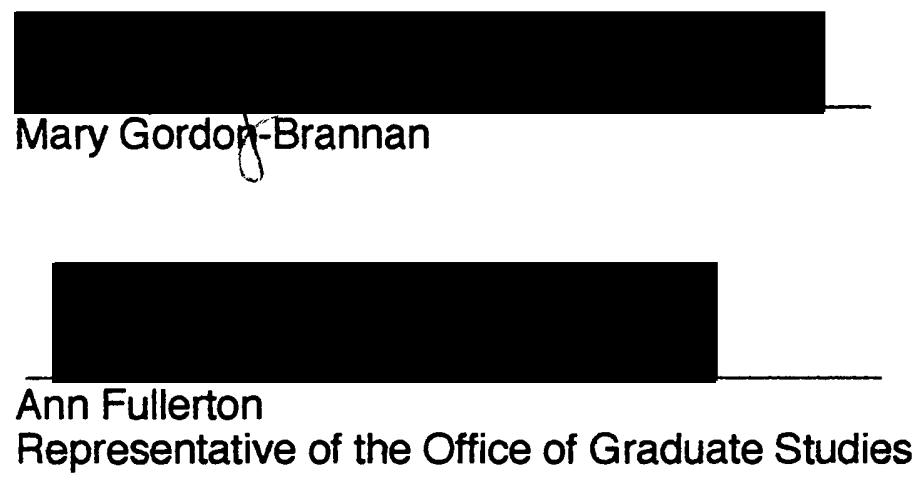

DEPARTMENT APPROVAL:

Stephen A. Kosokbff, Chair

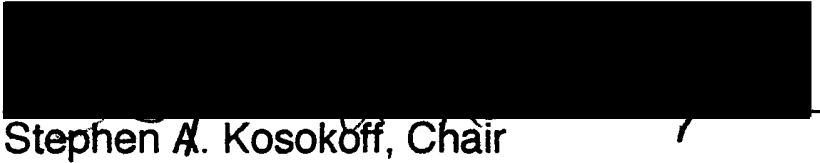

Department of Speech Communication

ACCEPTED FOR PORTLAND STATE UNIVERSITY BY THE LIBRARY

by on 79 youk 1995. 


\section{ABSTRACT}

An abstract of the thesis of Staci Lee Johnson Ball for the Master of Science in

Speech Communications: Speech and Hearing Sciences presented January 30 , 1995.

Title: Methods of Language Assessment: A Survey of Oregon Public School Speech-Language Pathologists.

Much advice has been published in the last 40 years that has attempted to aid speech-language pathologists in choosing language assessment tools (e.g., Danwitz, 1981 \& Darley, 1979 ). Questions have arisen about what tests are actually being used in public schools and the reasons for those tests being used over other tests. The data bank of information is minimal in this area as only one study has appeared in the literature in which Wilson, Blackmon, Hall, \& Elcholtz, (1991), conducted a State survey of currently used language assessment instruments.

The primary research question to be answered was: What methods of language assessment are being used in Oregon? Secondary questions to be answered were: (a) What factors influence the selection and use of the chosen procedures?, (b) What are the dates of development of the tests used most frequently, (c) By what means do the public school clinicians keep themselves current with new trends and information in the field? 
There were 567 questionnaires mailed out to Oregon Speech-Language Pathologists who worked in the public school setting and served children 4-9 years of age. Of the 297 respondees, only 4 reported not using any formal instruments for language assessment. Results show 9 main standardized tests were used for measuring expressive language by the majority of the respondents. Listed in order of frequency of use, they are: TOLD, EOWPVT, WORD test, CELF, LPT, SPELT, ASSET, TOPS, and the PLS. For receptive language, also in order of frequency of use, the 10 main tests were as follows: PPVT, TOLD, CELF, TACL, ASSET, BOEHM, PLS, ROWPVT, BRACKEN, and the LPT. Factors that influenced the selection and use of specific tests included: personal experience; ease of administration; time restraints; budgets and availability of tests and district protocols for assessments. Dates of publication, new and revisions, for both the expressive and receptive tests used ranged from 1983 - 1990. At the time of this survey, the main ways that clinicians were keeping themselves current for new tests on the market were word of mouth from associates, inservices on new tests, and reading new information in journals. 


\title{
METHODS OF LANGUAGE ASSESSMENT: A SURVEY OF OREGON PUBLIC SCHOOL SPEECH-LANGUAGE PATHOLOGISTS
}

\author{
by
}

STACI LEE JOHNSON BALL

\begin{abstract}
A thesis submitted in partial fulfillment of the requirements for the degree of
\end{abstract}

\author{
MASTER OF SCIENCE \\ in \\ SPEECH COMMUNICATIONS: \\ SPEECH AND HEARING SCIENCES
}

Portland State University

1995 


\section{DEDICATION}

This thesis is dedicated to my husband, Joe Ball, who more than anyone else, encouraged me to finish it and did many countless hours of "parenting" so that I could get it done. It is also dedicated to Jim and Carrol Johnson, my parents, who provided support and to my brother, Nathaniel, whose speech first got me interested in this field. 


\section{ACKNOWLEDGEMENTS}

I would like to give my deepest thanks to Joan McMahon, my thesis and academic advisor, for all of her help during the last, long, four years. Her encouragement and support, both on campus and off, was invaluable to me and enabled me to complete my thesis even after I had left the program and found " a real job".

Thank you to other committee members Mary Gordon-Brannan and Ann Fullerton for their helpful comments and guidance.

Thank you also to Dr. Doug Martin, who created an incredible computer program to put into order the huge amount of data that needed to be compiled.

Finally, I dedicate this work to two people who have both influenced my life in unique ways. First to my husband, Joe, who kept bugging me to finish this thesis just for me, so that I could have the degree in my hand and not give any more excuses about why I never finished. And finally to my beautiful daughter Andrea Taylor, whose arrival seemed to put my career on-hold for awhile. May she always remember that her mommy loves her career and worked very hard to get to where she is today but that she will aiways be first in my life, above any job. 
ACKNOWLEDGEMENTS .

LIST OF TABLES . . . . . . . . . . . . . . . . . . . vi

CHAPTER

I INTRODUCTION AND STATEMENT OF PURPOSE. . . . . 1 Introduction. . . . . . . . . . . . . 1

Statement of Purpose. . . . . . . . . . . . 3

II REVIEW OF THE LITERATURE. . . . . . . . . . . . 4

Historical Data.

Assessment Changes. . . . . . . . . . 4

Recent Studies of Language Assessment Procedures. $\quad 7$

III METHODS. . . . . . . . . . . . . . . . 11

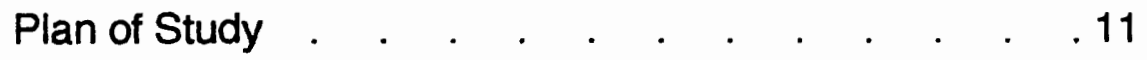

Subjects. . . . . . . . . . . . . . . 11

Questionnaire. . . . . . . . . . . 12

Procedures. . . . . . . . . . . . . . . . 13

Analysis Techniques

IV RESULTS AND DISCUSSION. . . . . . . . . . . . 15

Results. . . . . . . . . . . . . . . . 15

Discussion. . . . . . . . . . . . . 26

V SUMMARY AND IMPLICATIONS. . . . . . . . 33

Summary. . . . . . . . . . . . . . . . . . . . . . .

Implications. . . . . . . . . . . . . . 35

Clinical Implications

Research Implications 
REFERENCES. . . . . . . . . . . . . . . . 38 APPENDIXES
A QUESTIONNAIRE. . . . . . . . . . . 42
B COVER LETTER. . . . . . . . . . . . . . . 45
C EXPRESSIVE LANGUAGE TESTS RANKED BY FMS. . 47
D EXPRESSIVE LANGUAGE TESTS REFERENCED. . . . 51
E RECEPTIVE LANGUAGE TESTS RANKED BY FMS. . $\quad .57$
F RECEPTIVE LANGUAGE TESTS REFERENCED. . . 60 


\section{LIST OF TABLES}

TABLE

PAGE

1 Reported Methods of Assessment of Expressive

Language. .

2 Reported Methods of Assessment of Receptive

Language. . . . . . . . . . . . 17

3 Instruments Used to Assess Expressive Language. . 19

4 Instruments Used to Assess Receptive Language. . 20

5 Possible Factors that Influence the Selection and

Use of Instruments and Methods. . . . . . 23

6 Dates of Publication for Top Tests. . . . . . 24

7 Means of Keeping Current on Testing Procedures. . 25 


\section{CHAPTER I}

\section{INTRODUCTION AND STATEMENT OF PURPOSE}

\section{Introduction}

When PL 94-142, The Individuals with Disabilities Education Act, went into effect in 1975, it put into law the belief that all children deserve an appropriate education regardless of disability. As part of the statute, the federal government also required that Individual Education Programs (IEPS) be written for each child identified as disabled based on a comprehensive assessment administered by trained personnel. The assessment for students with language disorders must include one standardized test of language (Abraham \& Stoker, 1988).

Language assessment has been in continuous change over the last 30 years. In the last decade alone, a multiplicity of new techniques and methods for assessing language have emerged. Over 150 published instruments have been developed for the purpose of assessing language in children (Wilson, Blackmon, Hall, \& Elcholtz, 1991). Due to this rapid increase in the number of assessment instruments for language and the concomitant expansion of language research, it is possible that the needs of public school children are not being adequately served at this time. Wilson et al., in their 1991 California study, demonstrated that clinicians in their state do combine previously learned assessment material with knowledge acquired from workshops, published research material, and networking within the field to maintain currency on assessment measures. The authors, however, stated that the "results of this survey should not be generalized to other states" (p.39). 
Typically, language assessment both precedes and accompanies the language management program; therefore, knowledge and use of appropriate language assessment procedures are a fundamental professional concern of speech-language pathologists (Pickett \& Flynn, 1983). The focus of the Pickett and Flynn study was to determine the tools, standard and non-standard, actually employed for language assessment in adults with mental retardation.

With the exception of Pickett and Flynn (1983), very little information is available to aid in determining which methods of language assessment are currently employed by clinicians. Muma, Webb, and Muma published an account of language assessment procedures in 1979, basing their account on a study conducted in 84 higher education institutions. In 1983, Muma, Pierce, and Muma repeated the study in 76 higher education programs. Whether these tests were chosen to be used in the field was found to correlate to the clinician selecting instruments that were commonly employed during preprofessional training.

With all of the tests on the market today and in the school systems, a problem arises in knowing which tests are available and in choosing which test to use when assessing individual children. This is important because the manner chosen to assess a child and the diagnostic information received influences the IEP content and how the management procedures are carried out.

It would be appropriate to conduct a survey of Oregon public school clinicians to obtain information on what types of assessment tools are being used to test language. Data do not exist in the state of Oregon regarding current language assessment practices; therefore, a baseline study is important. in addition, future clinicians entering the work field should know which types of 
materials are being used in the state. Finally, it is important for school clinicians to keep current in the area of language assessment as new measures are researched and introduced annually.

\section{Statement of Purpose}

The purpose of this study was to determine what methods of assessing 4to 9-year-old children's language were currently being employed by Oregon public school speech-language pathologists. The primary research question to be answered was: What methods of language assessment are being used in Oregon? Secondary questions to be answered were: (a) What factors influence the selection and use of the chosen procedures?, (b) What are the dates of development of the tests used most frequently?, (c) By what means do the public school clinicians keep themselves current with new trends and information in the field? 
CHAPTER II

\section{REVIEW OF THE LITERATURE}

\section{Historical Data}

In 1975, P.L. 94-142, The Individuals with Disabilities Act, was passed by Congress. According to the law, all children between 3 and 21 years of age shall receive a "free appropriate public education which emphasizes special education and related services designed to meet their unique needs" (Heward \& Orlansky, 1992, p. 44). Individual state agencies must comply with five main components of the law, but the two that effect this study are: (1) developing an individual education program (IEP) for every child in the state who is disabled, and (2) identifying and placing children who are disabled by means of testing and evaluation procedures that do not discriminate. Identification and placement decisions of where a child is to be placed must not be made on the basis of one test score (Heward \& Orlansky, 1992). Speech-language pathologists, therefore, must have a battery of tests at their disposal to test children in the areas of their particular need. Each individual speech-language pathologist determines what tests are used and how they are chosen.

\section{Assessment Changes}

There have been hundreds of language assessment tools created in the past 40 years. In the 1950s, the approach to language assessment was secondary to 
assessing articulation with normative data (Lund \& Duchan, 1983). This entailed gathering a child's speech sample and then comparing the results to that of normal children. Language was informally being assessed in the speech sample. The focus of the testing was to determine a cause for the speech disorder (Launer \& Lahey, 1981), not to look at language directly. As informal language data were gathered, they started to appear in published form (McCarthy, 1954), but these test results began to be seen as subject to the biases of the administrator and the findings determined by the skills of the examiner. These factors contributed to the rise in objective test instruments for language in the 1960s ( Carrow-Woolfolk \& Lynch, 1982).

The 1960 s saw change in the area of language assessment. Less attention was paid to determining causal factors of the language disorder. Language was now seen as being made up of many parts or domains (i.e., semantics, syntax, morphology, phonology, and pragmatics). The deficit could now be identified by strengths and weaknesses in these language domains (Launer \& Lahey, 1981). If one of the above areas was weak, it could be made stronger by intervention in that area. The Illinois Test of Psycholinguistic Abilities (ITPA) (Kirk, McCarthy, \& Kirk, 1968) is one of the best examples of testing from this time. Other examples of instruments published at this time are The Assessment of Children's Language Comprehension (Foster, Giddan, \& Stark, 1969) and the Test of Auditory Comprehension of Language (Carrow, 1973).

The production of standardized tests continued into the 1970s. As more objective tests were put into the market ( e.g., the Carrow Elicited Language Inventory, Carrow, 1974; and Bankson Language Screening Test, Bankson, 1977), language sampling began to reappear, but this time with normative data made available for interpreting data (Lee, 1974). In this era, a move was 
made to examine closer the use, content, and form of language (Bloom \& Lahey, 1978). Pragmatics became very important as speech-language pathologists began to focus on the speaker's intent and the context of the situation.

The theoretical systems of language development research continued to change as different hypotheses were developed and either proven or disproven. Much advice has been published in the last 40 years ( e.g., Danwitz, 1981; Darley, 1979; Launer \& Lahey, 1981) in an attempt to aid speech-language pathologists in what assessment tools to choose when selecting testing materials. Many researchers have reported that the field is beginning to move away from standardized testing because standardized tests do not provide a complete picture of the child and may not be valid (Danwitz, 1981; Lass, 1982 ). As we have seen, however, since the enactment of PL 94-142 many professionals are obligated to assess children with standardized tests. This in turn creates more tests on the market to be purchased which refers back to the original questions of this paper, that is, what assessment materials do speechpathologists chose and why do they chose them? Danwitz (1981) maintained that a clear picture of the child cannot be seen if only standardized tests are used, and that standardized tests are not as effective as they may appear. Darley ( as cited in Wilson et al., 1991) also cautioned that some speechlanguage pathologists may be impressed with the contents of a test just because the test is in published form.

Many professionals strongly advise the use of both formal and informal procedures to measure language. Carrow-Woolfolk and Lynch (1982) observed that not all examiners are equally qualified to diagnose a language disorder. The innate ability of clinicians to use experiential knowledge and their senses of vision 
and hearing have been taken into consideration (Meitus, 1983). From here, clinicians then use formal instrumentation to verify their hypotheses. It is not satisfactory, however, to write a diagnosis on the hypotheses if the objective findings do not support the original opinions. There is a broad range in the views on formal and informal testing, from Berry (1980), who completely omitted formal testing claiming "that they seldom tell us what we need to know" (p. 7), to Kamhi (1984), who only used formal testing because it keeps one from " falling prey to the lure of descriptive views of childhood language disorders" (p. 233).

\section{Recent Studies of Language Assessment Procedures}

Little evidence is available to aid in determining which methods of language assessment are commonly used by clinicians. Muma, Webb, and Muma, in 1979, did publish an account of procedures used in 84 education institutions. This procedure was repeated in 1983 by Muma, Pierce, and Muma with 76 education programs. In both cases, the use of descriptive and psychometric approaches were reported. They also provided a list of the most frequently mentioned procedures. There was no indication that the use of those instruments reported in the survey did or did not transfer from the educational institution to the field. Preparation programs should be aware of what is being used in their regional area to guide in the preparation of new speech-language pathologists.

A study by Wilson et al., published in 1991, was actually conducted in 1988. The authors conducted a survey of language assessment in California public schools to determine the methods of assessing children's language used by public school clinicians and what influenced them to use those procedures. 
There were 500 subjects, chosen from the 1988 Directory of the California Speech-Language-Hearing Association, who received a two-page questionnaire. The return rate of the survey was $53 \%$. The questionnaire called for responses regarding their current methods of language assessment. Questions that were asked included: (a) did the clinicians use both formal and informal means of assessing; (b) what other materials, if any, were used; and (c) did the clinicians do any language sampling? Responses also included the five most frequently used expressive and receptive tests. Ten forced-choice questions were asked to help explain why they chose the particular tests.

When the surveys were returned, Wilson et al. (1991) found that the 266 clinicians responding had a mean of 11.7 years of working in the schools. The Expressive One-Word Picture Vocabulary Test (Gardner, 1985 ), Test of Language Development-Primary (TOLD-P) ( Hammill \& Newcomer, 1982), and Clinical Evaluations of Language Functions (CELF) ( Semel \& Wiig, 1980) ranked first, second, and third, respectively for expressive tests used. For receptive tests used, the Peabody Picture Vocabulary Test (Dunn \& Dunn, 1981) ranked first with the CELF and the TOLD-P, second and third respectively. Over $90 \%$ of the clinicians responding said that they incorporated new means of assessment based on workshops, other clinicians, and experience as their means of keeping current. The results indicate that clinicians do incorporate new means of assessment rather than continuing to use the same tests they gave when first beginning in the field.

Wilson noted that a variable in her survey that should have been asked differently was the question of language sampling ( K. S. Wilson, personal 
communication, March 12, 1992). The author suggested that instead of just asking if the clinicians used language sampling, a more appropriate question would have been if they formally transcribe the language sample; and do they formally transcribe it for diagnosis or do they only use it informally for their own treatment.

Pickett and Flynn (1983) examined a survey of language assessment tools used in assessing persons diagnosed as mentally retarded. The authors also wanted to determine the variety and frequency of selection of language assessment tools speech-language pathologists used. They recommended the modification of existing materials because there have not been appropriate assessment tools created for this population. They also suggested the development of new tools which place an emphasis on the child's environment and advocated a battery of standard tests and nonstandard measures be used to detail a "baseline of communicative behavior function." The results of this study were determined from a national survey that had a return rate of $50 \%$ from the 108 facilities surveyed. Overall results indicated a large array of assessment instruments were used, but most diagnostic decisions were made with informal measures only.

Abraham and Stoker provided a language assessment analysis for children who are hearing impaired in their 1988 article. Research indicated that, until PL 94-142, most teachers of the hearing impaired used informal assessment measures to assess students. After the implementation of PL 94-142, professionals working with the hearing impaired became obligated to assess students formally using the child's primary mode of communication. Abraham and Stoker's purpose was to determine what instruments were currently being 
used to evaluate hearing impaired students. Results of their survey indicated that, because of the lack of formal instruments for the hearing impaired, tests standardized on hearing children were being modified for use. The authors also found language sampling being used consistently for assessment.

With all of the above research in language assessment, one can observe that finding what assessment tools the majority of speech-language pathologists use in the public schools is difficult. The results not only vary from clinician to clinician, but also from one regional area to the next. Carrow-Woolfolk and Lynch (1982) advised against using tests on the basis of only availability and familiarity, but past research (Muma, Pierce, \& Muma, 1983) has found that the use of most instruments in the field depends upon whether or not the assessment instruments had been taught to the speech-language pathologists during their pre-professional preparation. Carrow-Woolfolk and Lynch (1982) do admit that with all of the research found in the area of language assessment, clinicians may feel overwhelmed and impatient with the fact that they may need to keep changing procedures.

Other than the above-mentioned studies, little evidence exists to help us determine which of the hundreds of methods are most currently employed by speech-language pathologists. This current study is aimed at gathering a consensus for Oregon, in order to determine which language assessment tools are being used, how the tools are being selected, and how Oregon public schools clinicians keep themselves current in the changing area of language assessment. 
CHAPTER III

METHODS

Plan of Study

This study utilized a group description design to determine the types of language assessment tools Oregon public school clinicians use. When the results and information were tabulated and graphed, the kinds of materials public school clinicians use and what helps them decide to use these tools were observed and reported.

\section{Subjects}

The pool of prospective subjects of this study was selected from the 1992 directory of the Oregon Speech-Language-Hearing Association and the 19921993 Directory of Oregon Public Schools. The group was reduced by choosing those who listed their place of employment as a school district or an educational service district. This yielded 567 subjects who were sent the questionnaire. They were asked to complete the questionnaire if the population they serve includes children from 4 to 9 years of age. A $52 \%$ return rate was achieved with 297 clinicians returning useable surveys. The years of providing service to the 4 to 9 year age group by the 297 subjects ranged from .5 to 40 years, with a mean of 10.89 years. 


\section{Questionnaire}

The questionnaire used in this study and by Wilson et al. (1991) is included in Appendix A. The questionnaire elicited information pertaining to the number of years subjects had worked in the field and current methods of language assessment. The clinicians were asked to indicate both formal and informal methods of assessing language, and space was provided to describe in detail what they use.

The speech-language pathologists were asked to indicate as many testing procedures from the selection that were most often employed and to indicate what five formal language tests they use for both receptive and expressive testing in order of frequency of use. Room for explanation was provided at the bottom of the questionnaire. A section was also included in which the clinicians were asked if they obtain a language sample and, if so, how often. A question not asked in the California study has been added to determine if the clinicians formally transcribe the language sample or if they only use it informally for treatment purposes.

One portion of the questionnaire consisted of 10 forced choices that referred to the clinicians' rationale for their selection of language assessment tools and approaches. The respondents checked one of five responses to each statement: strongly agree, agree, neutral, disagree, or strongly disagree.

Clinicians were encouraged to include written comments that might expand upon their responses (Wilson et al., 1991). 
Procedures

A two-page questionnaire, (Appendix A) the same used for the California study (Wilson et al., 1991 ) with the additional questions on language sampling, was mailed with a cover letter (Appendix B) explaining the objectives and stating that participation was optional and that their answers will not be labeled with their names so their responses would remain anonymous. The return postage was paid and the envelopes pre-addressed, in order to elicit a better return.

\section{Analysis Techniques}

Data analysis procedures included Frequency of Mention, and Weighted Use scores (Goh, Teslow, \& Fuller, 1981; Abraham \& Stoker, 1988) and the reporting of percentages and means. The formal assessment procedures noted were listed in the order of frequency of use, for both expressive and receptive language, and were given a Frequency of Mention Score (FMS) (Goh et al., 1981). To obtain a FMS, the five tests mentioned in the formal assessment area were ranked by frequency of use. If the clinicians mentioned the test in their top five it was counted. Additionally, tests were assigned a FMS rank. Instruments were also given a Weighted Use Score (WUS), according to the ranking on the list of each clinician's five most frequently used tests (Abraham \& Stoker, 1988). To find a WUS score, each of the five tests sent in by the respondees in all surveys was scored. All respondents rankings were added. Each instrument cited as the number one choice was given a point value of five. Instruments ranking 2nd through 5th were given decreasing point values from 4 to 1 , respectively. Additionally, the tests were assigned a WUS rank. The raw data were reduced to tables and box graphs to illustrate the information. 
The forced-choice questions were tabulated by using raw data and a percentage score. For representing the responses in a physical representation, the forced choice questions were represented in tables by raw data. This method was continued until all the forced choices had been tabulated. Answers were separated by questions into groups for the box graphs. 


\section{RESULTS AND DISCUSSION}

\section{Results}

The purpose of this study was to determine what methods of assessing 4to 9-year old children's language are currently being employed by Oregon public school speech-language pathologists. Secondary purposes were to determine factors for possible influences for selection, how recently the tests being used were developed, and how the clinicians keep current in regard to new testing information. A state-wide survey was sent out to speech-language pathologists working in the public schools that served the above age group. Results were tabulated and are presented as follows.

The primary question posed by this study was: What methods of language assessment are currently being used in the State of Oregon? This question can be answered in three parts. First, this study found that a combination of three main methods were currently in use; specific published, formal instruments; clinician-devised informal methods; and, other methods that included the use of language sampling. Although all combinations of these three were used, it can be noted by the results reported in Table 1 that $99 \%$ of the respondents used some form of published, formal instrument to assess expressive language.

The respondents reporting that they used both published, standardized instruments and clinician-devised, informal methods of assessment of expressive language numbered 91 (see Table 1). An additional 81 included other methods as well as formal and informal. Use of published, standardized instruments only was reported by 58 respondents, and 63 checked "other" as well as published 
tests. Three clinicians reported using only clinician devised informal methods.

Table 1

Reported Methods of Assessment of Expressive Language

METHODS USED

NUMBER

PERCENT

Published, formal instruments

91

$31 \%$

and clinician devised, informal

methods

Published, clinician-devised, and

81

$27 \%$

other methods

Published, formal instruments

63

$27 \%$

and other

Published, formal instruments

58

$20 \%$

Clinician-devised, informal method

3

$1 \%$

Clinician-devised and other

1

$0 \%$

$\mathrm{N}=297$

Note - Percentages rounded to the nearest whole $\%$.

The results for methods of assessing receptive language are shown in

Table 2. Again note that $99 \%$ of the respondents mentioned using at least some form of published, formal testing. Use of published, standardized and informal, clinician-devised measures was indicated by 89 , while an additional 43 also listed other methods. Those who indicated using only formal instruments numbered 131,33 also checked "other," and one checked off "informal \& other" only. 
Table 2

Reported Methods of Assessment of Receptive Language

METHODS USED

NUMBER

PERCENT

Published, formal instruments

131

$44 \%$

Published, formal instruments and clinician-devised, informal methods

89

$30 \%$

Published, clinician-devised, and other methods

43

$14 \%$

Published and other methods

33

$11 \%$

Clinician-devised and other

1

$0 \%$

$N=297$

Note: percentages rounded to the nearest whole $\%$

When clinicians responded "other," they were asked to write next to it what they used. Samples of these responses included language samples, parent/teacher reports, observation of classroom, environmental sample, records, rating scales, checklists, developmental scales, homework, screening, other specialists, probes, and criterion referenced norms.

The second part in answering the primary question was to identify the specific published-formal instruments that were used to assess expressive and receptive language in the state of Oregon. Fifty-seven instruments were mentioned at least once as a formal measure of assessing expressive language. 
In Table 3 these tests are listed by both Frequency of Mention Score (FMS) and Weighted Use Score (WUS) scores and rankings. When a test had a revised edition, both the new and old forms were counted together under the same name. The mean of the FMS scores was 119.77 with the range being from 49211. Tests were not counted that were lower than 49 because, at this score, both the FMS and WUS scores took a sharp drop showing a decrease in both mention and use overall and scores begin to reflect individuals rather than the group. Refer to Appendix C for complete expressive FMS and WUS rankings of all the $\mathbf{5 7}$ tests named. Refer to Appendix $D$ for full test names, dates of publishing, and authors in FMS ranked order. The Test of Language Development (TOLD) (Newcomer \& Hammill, 1977; Hammill \& Newcomer, 1982), and the Expressive One Word Picture Vocabulary Test (EOWPVT) (Gardner, 1979), achieved first and second ranking in both Frequency Mention Scores and Weighted Use Scores. Following the TOLD and the EOWPVT respectively in FMS ranking were The WORD test (Jorgensen, Barrett, Huisingh, \& Zachman, 1981), Clinical Evaluation of Language Function (CELF) ( Semel \& Wiig, 1980), Language Processing Test (LPT) (Richard \& Haner, 1985), the Structured Photographic Expressive Language Test (SPELT) (Werner \& Krescheck, 1983), Assessing Semantic Skills through Everyday Themes (ASSET) (Barrett, Zachman, Huisingh, 1990), the Test of Problem Solving (TOPS) (Zachman, Jorgensen, Huisingh, \& Barrett, 1984), and the Preschool Language Scale (PLS) (Zimmerman, Steiner, \& Pond, 1979). 
Table 3

Instruments Used to Assess Expressive Language

\begin{tabular}{llclc}
\hline TEST & FMS & FMS rank & WUS & WUS rank \\
\hline TOLD & 211 & 1 & 826 & 1 \\
EOWPVT & 179 & 2 & 632 & 2 \\
WORD TEST & 140 & 3 & 407 & 4 \\
CELF & 127 & 4 & 458 & 3 \\
LPT & 113 & 5 & 338 & 5 \\
SPELT & 94 & 6 & 263 & 7 \\
ASSET & 93 & 7 & 303 & 6 \\
TOPS & 72 & 8 & 161 & 9 \\
PLS & 49 & 9 & 172 & 8 \\
& & & & \\
\hline
\end{tabular}

Receptively, 47 instruments were mentioned at least once as a formal measure of assessing receptive language. These results are presented in Table 4 by both FMS and WUS scores and rankings. Again both original and revised forms were counted together under the same name. The mean of the FMS scores was 100.5 with the range being from 38-245. Scores lower than FMS 38 were not counted because they do not represent the group as a whole and the WUS no longer correlate on a 1:1 basis. Refer to Appendix $E$ for complete receptive FMS and WUS rankings of all 47 tests named. Refer to Appendix F for full test names, dates of publishing, and authors in FMS ranked order. 
Table 4

Instruments Used to Assess Receptive Language

$\begin{array}{llll}\text { TEST FMS FMS rank WUS WUS rank } & \text { W }\end{array}$

\begin{tabular}{lllll}
\hline PPVT & 245 & 1 & 998 & 1 \\
TOLD & 176 & 2 & 633 & 2 \\
CELF & 122 & 3 & 433 & 3 \\
TACL & 114 & 4 & 374 & 4 \\
ASSET & 89 & 5 & 298 & 5 \\
BOEHM & 85 & 6 & 226 & 6 \\
PLS & 49 & 7 & 177 & 7 \\
ROWPVT & 48 & 8 & 151 & 8 \\
BRACKEN & 39 & 9 & 106 & 9 \\
LPT & 38 & 10 & 106 & 10 \\
\hline
\end{tabular}

The Peabody Picture Vocabulary Test (PPVT) (Dunn \& Dunn, 1981) and the TOLD achieved the first and second rankings respectively by both FMS and WUS of all the receptive tests listed. Following these tests were the CELF, the Test for Auditory Comprehension of Language (TACL) (Carrow, 1973), the ASSET, the Boehm Test of Basic Concepts (Boehm, 1969), the PLS, the Receptive One-Word Picture Vocabulary Test (ROWPVT) (Gardner, 1985), the Bracken Basic Concepts Scale (Bracken, 1984), and the LPT.

The third and final part in finding a complete answer for the primary question of what methods do Oregon public school speech-language pathologists use to assess language was to examine language sampling. Of the 297 
clinicians who responded to the survey, 17 reported that they do not do any language sampling. Of the 280 that do acquire samples, 266 provided a percentage of language assessments in which they did so. The resulting range was $5 \%$ to $100 \%$, with a mean of $69 \%$. Whether these samples were formally or informally transcribed was the final question on the survey. There were 287 respondents to this question. Out of these, there were 272 usable answers; 54 clinicians formally transcribe every language sample they take, 150 informally transcribe the language sample and use it for treatment, and 68 responded by saying that they use both formal and informal methods of transcription. Of the respondents reporting they use some form of formal transcription of the language sample the following measures were mentioned: Mean Length of Utterance (MLU) and Brown's Stages (Brown, 1973); Developmental Sentence Score (DSS) (Lee, 1974); Language Sampling, Analysis, and Training (LSAT) (Tyack and Gottsleben, 1974); content, form, and use (Bloom \& Lahey, 1978); Arwood PRagmaticism Institute COmmunication Therapy (APRICOT) (Arwood, 1985); Portland Public School Plan; Systematic Analysis of Language Transcripts (SALT) (Miller, J. \& Chapman, R.); Assessing Structural Stages (ASS) (Miller, 1981); Beaverton School District analysis; and the Index of Productive Syntax (IPSYN) (Scarborough, 1990).

There were three secondary questions investigated in this study. The first was what factors influence the selection and use of the procedures that the clinicians have chosen to use? The responses to statements reflecting possible influences on selection of assessment methods are presented in Table 5. They are listed in rank order A-G with $\underline{A}$ being the most important influence and $\underline{G}$ being the least important. Influences included the following: the clinician's knowledge and education, instruments that are mandated or suggested for use 
by supervisors and districts, time to assess children, appropriate materials to assess children, depending on normed instruments for placement, and relying on both tests results and personal judgements.

Of all the responses reflecting possible influences on selection of assessment methods, $96 \%(\mathrm{~N}=286)$ of the respondents agreed with the statement that they use the instruments based upon their knowledge and education. The next factor of importance is that $60 \%(N=180)$ of the clinicians agreed that they rely more upon their own judgement and less upon test results as they gain more experience. The third factor of importance is that $57 \%$ $(\mathrm{N}=168)$ of the respondents agree with the statement that they would depend less upon normed instruments if they were not necessary for placement. The fourth factor, with an agreement still above 50\%, at 52\% ( $N=154)$ agreement clinicians reported that they have adequate materials for assessment. This does however, leave $48 \%$ who do not have appropriate assessment materials. The final three responses of influence factors show that clinicians overall do not have enough time to assess a child appropriately to their satisfaction, $63 \%(N=185)$, and that $26 \%(\mathrm{~N}=78)$ agreed with the fact that their district mandates the tests to be used by providing a written list, while $40 \%(N=118)$ said that they use instruments that are suggested by their district/supervisor, but not mandated.

The next secondary question to be answered was to determine how recently the tests being used were developed. In Table 6 the top 9 expressive tests and the top 10 receptive tests have been listed with their publication dates. Note here that if the test has been revised only the most current date has been included. The earliest publication is of the PPVT which was 1981 and the latest was 1990 of the revised version of the PLS and the WORD test. 
Table 5

Possible Factors Influencing the Selection and Use of Instruments and Methods

Strongly

Strongly

Agree Agree Neutral Disagree Disagree

A.

I use assessment instruments

that are based upon my

knowledge and education.

$\begin{array}{ccccc}181 & 105 & 10 & 1 & 0 \\ 61 \% & 35 \% & 3 \% & <1 \% & 0 \%\end{array}$

B.

I find that, with experience, I am

$54 \quad 126$

relying more upon my own

judgment and less upon test

$\begin{array}{lllll}18 \% & 42 \% & 25 \% & 13 \% & 2 \%\end{array}$

results.

C.

I would depend less upon normed

$\begin{array}{lllll}49 & 119 & 54 & 68 & 7\end{array}$ instruments if the results weren't

$17 \%$

$40 \%$

$18 \%$

$23 \% \quad 2 \%$

necessary for placement.

D.

I have enough of the appropriate

materials for adequate assessment.

$\begin{array}{ccccc}26 & 128 & 53 & 80 & 10 \\ 9 \% & 43 \% & 18 \% & 27 \% & 3 \%\end{array}$

E.

I use assessment instruments which are suggested by my supervisor/district.

$\begin{array}{lllll}24 & 94 & 95 & 38 & 46\end{array}$ $8 \% \quad 32 \% \quad 32 \% \quad 13 \% \quad 15 \%$

F.

I have enough time to assess each child to my satisfaction.

11

$\begin{array}{lllll}11 & 71 & 30 & 133 & 52\end{array}$

$4 \% \quad 24 \% \quad 10 \% \quad 45 \% \quad 18 \%$

G.

I use assessment instruments which are mandated by my supervisor/district.

39

$\begin{array}{llll}39 & 70 & 72 & 77\end{array}$

$13 \% \quad 13 \% \quad 24 \% \quad 24 \% \quad 26 \%$ 
Table 6

Dates of Publication for Top Tests

EXPRESSIVE TESTS

\begin{tabular}{lllc} 
TEST & FMS & FMS rank & Date of Publication \\
\hline TOLD & 211 & 1 & 1988 \\
EOWPVT & 179 & 2 & 1983 \\
WORD TEST & 140 & 3 & 1990 \\
CELF & 127 & 4 & 1987 \\
LPT & 113 & 5 & 1985 \\
SPELT & 94 & 6 & 1983 \\
ASSET & 93 & 7 & 1988 \\
TOPS & 72 & 8 & 1985 \\
PLS & 49 & 9 & 1990
\end{tabular}

RECEPTIVE TESTS

\begin{tabular}{lllc} 
TEST & FMS & FMS rank & Date Published \\
\hline PPVT & 245 & 1 & 1981 \\
TOLD & 176 & 2 & 1988 \\
CELF & 122 & 3 & 1987 \\
TACL & 114 & 4 & 1985 \\
ASSET & 89 & 5 & 1988 \\
BOEHM & 85 & 6 & 1986 \\
PLS & 49 & 7 & 1990 \\
ROWPVT & 48 & 8 & 1983 \\
BRACKEN & 39 & 9 & 1984 \\
LPT & 38 & 10 & 1895 \\
& & & \\
\hline
\end{tabular}


The last secondary question to be answered is by what means do public school speech-language pathologists keep current in regard to testing changes. Table 7 provides the data pertaining to this answer. The top four answers to this question were that clinicians keep current by (a) combining new and old methods, keeping what works and discarding what does not based upon their experience $=96 \%$; (b) incorporating new means of assessment by information shared informally by other clinicians $=91 \%$; (c) incorporating new information based upon workshops attended $=91 \%$; and $(d)$ incorporating new information based upon research that is read $=69 \%$.

Table 7

Means of Keeping Current on Testing Procedures

\begin{tabular}{|c|c|c|c|c|c|}
\hline & $\begin{array}{l}\text { Strongly } \\
\text { Agree }\end{array}$ & Agree & Neutral & Disagree & $\begin{array}{l}\text { Strongly } \\
\text { Disagree }\end{array}$ \\
\hline $\begin{array}{l}\text { I use a combination of old and } \\
\text { new methods, keeping what } \\
\text { works and discarding what does } \\
\text { not based on my experience. }\end{array}$ & $\begin{array}{c}193 \\
65 \%\end{array}$ & $\begin{array}{l}93 \\
31 \%\end{array}$ & $\begin{array}{l}5 \\
2 \%\end{array}$ & $\begin{array}{l}4 \\
1 \%\end{array}$ & $\begin{array}{c}2 \\
<1 \%\end{array}$ \\
\hline $\begin{array}{l}\text { I incorporate new means of } \\
\text { assessment into my program } \\
\text { which are shared informally with } \\
\text { me by other clinicians. }\end{array}$ & $\begin{array}{c}114 \\
38 \%\end{array}$ & $\begin{array}{l}156 \\
53 \%\end{array}$ & $\begin{array}{l}23 \\
8 \%\end{array}$ & $\begin{array}{l}3 \\
1 \%\end{array}$ & $\begin{array}{c}1 \\
<1 \%\end{array}$ \\
\hline $\begin{array}{l}\text { I incorporate new means of } \\
\text { assessment into my program } \\
\text { based upon workshops which } \\
\text { I attend. }\end{array}$ & $\begin{array}{l}131 \\
44 \%\end{array}$ & $\begin{array}{l}138 \\
47 \%\end{array}$ & $\begin{array}{l}21 \\
7 \%\end{array}$ & $\begin{array}{l}7 \\
2 \%\end{array}$ & $\begin{array}{l}0 \\
0 \%\end{array}$ \\
\hline $\begin{array}{l}\text { I incorporate new means of } \\
\text { assessment into my program } \\
\text { based upon research I read. }\end{array}$ & $\begin{array}{l}74 \\
25 \%\end{array}$ & $\begin{array}{l}132 \\
44 \%\end{array}$ & $\begin{array}{l}65 \\
22 \%\end{array}$ & $\begin{array}{l}24 \\
8 \%\end{array}$ & $\begin{array}{l}2 \\
<1 \%\end{array}$ \\
\hline
\end{tabular}


Discussion

The methods of language assessment that were currently being used in Oregon in 1993 were a combination of formal-published tests, informal clinician devised tests and some form of language sampling. The results obtained could be a result of criteria from the state of Oregon for qualification of services. According to the Oregon State Department of Education (1993), a pupil meets the criteria for language remediation services based upon the results of either (a) a minimum of two diagnostic tests in the areas of language development specified as syntactic, semantic, morphological, phonological, and pragmatics; or (b) one standardized test in the previously mentioned language area and a spontaneous or elicited language sample (Oregon Administrative Rules, Chapter $581,1993)$.

A clear majority of clinicians in this study used published, standardized instruments as part of their language assessment, and many reported using them in combination with informal, clinician-devised methods. In addition, 272 respondents, $92 \%$ of the sample, reported using some type of language sample and either formally or informally transcribing it for diagnostic and treatment purposes.

There were many standardized instruments mentioned in this survey, but less than $1 / 4$ of them were mentioned by at least $10 \%$ of the respondents. The results showed that while many infrequently mentioned instruments were used to assess language in Oregon, expressive language was assessed overwhelmingly by 9 main instruments and receptive language was assessed by 12 main instruments. It could be that these instruments were selected for their wide scope during initial assessment, while instruments which probe one or two 
specific aspects of language were used less often or when a specific part of language needed to be tested. Another feature of these most common instruments which could have affected the frequency of mention score was the age range in which they were normed; those most frequently mentioned were normed for all or almost all of the age range of 4- to 9- years upon which this study focused.

Many factors appeared to influence the selection and use of the chosen procedures. It could be that the education and knowledge of the clinicians affected their test selection. It could also be that district and supervisor suggestions did have some influence, but it appeared that the clinician had a great deal of autonomy when determining how to best assess language, as they were free to choose test batteries without supervisor or district mandate. While published standardized instruments were widely used, over half of the respondents agreed with the statement that they would depend upon them less if the results were not necessary for placement of a child into a language program. In addition, $60 \%$ of the respondents reported that, as they developed more experience in the field, they relied more upon their own judgment than upon test results to determine a child's language treatment needs. Again, district and/or supervisor mandated assessment procedures may have had some effect upon the clinicians' chosen methods, if there were a certain number of tests from which they could choose.

Written statements from respondents indicated that the use of standardized instruments often confirmed clinical judgments. The results from formal testing were often used in conjunction with informal observation, teacher and parent reports, probes, and checklists that resulted in a more complete impression of a child's language performance. Whether or not the language 
samples were used for placement or treatment the samples were reported to give a "true representation" of the child's language performance.

Other factors that influenced test selection were testing time and adequacy of materials. The results showed that well over half of the respondents reported that they did not have enough time to perform adequate assessment, and others noted that diagnostic time was made at the expense of treatment or personal time. While having the adequate materials for assessment was a problem for a smaller number of the clinicians, written comments explained that they often borrowed tests from other clinicians or have purchased the tests at their own expense.

Answering the question of dates of development for the most commonly used tests, it was found that tests dates ranged from 1983 - 1990. Some of these dates included tests that had been revised. The results showed that the majority of tests used today were not recently published, but well normed. Reasons for this could be because clinicians used tests that they were most comfortable with, possibly due to training, or not having resources to keep up with the newest tests available, including revised editions. This report was supported by an examination of the list of frequently mentioned instruments; while several relatively new instruments were mentioned often, others which were much older appeared to remain clinically useful. New language tests have been created and can be combined with older tests to produce a thorough assessment of a child's language abilities. In most cases, it was a personal judgment as to which tests were used.

In response to the questions on keeping current to new trends in the area of assessment, the clinicians said that they depended more upon other professionals and word of mouth and used a combination of old and newly 
learned methods for their language assessment needs; rather than depending on journal articles or in-services to keep themselves current. It could be that lack of time and very heavy caseloads prevent clinicians from seeking out new testing materials on their own and keep them in the cycle of using what is familiar to them. Results indicate that the typical clinician in this study incorporated new means of assessment into their program rather than continuing to implement the same repertoire as that used when beginning the field. Workshops, information shared by other clinicians, and research that was read by the clinicians appeared to influence change in methods of assessment. Without a rank order of their responses, however, the results in current form make the determination of the greatest influence difficult.

The methods described by the clinicians responding to this survey may not be generalized outside of Oregon, as state-mandated assessment procedures may vary elsewhere. The group as a whole demonstrated attempts to combine the newest information with that information which had proven itself useful over time. As these professionals may very well conduct more assessment of language disordered children than any other sector of the speech-language pathology field, the methods of public school clinicians may be regarded as those which were well-tested and shown to be effective.

\section{Written Comments}

Written comments were added to the survey forms by $45 \%$ of the respondents ( $\mathrm{N}=133)$. Most of the remarks were in regard to time restraints, the survey itself, and personal informal methods in overall language assessment. The fact that standardized test results were mandated by the State of Oregon for placement in a language remediation program was pointed out by 66 of these respondents, while an additional 20 described using formal measures for 
placement, followed by personal informal probes for treatment goals. Both formal and informal methods had their place in language assessment according to 30 of the written remarks.

Advantages to using published, normed instruments were cited. Among these: (a) they confirm clinician judgment $(N=20)$, (b) help in making decisions in ambiguous cases $(\mathrm{N}=9)$, and (c) give the school district a number score for records $(\mathrm{N}=12)$. One clinician felt that there were too many labels on children today and using standardized tesis only helped to continue this. Other disadvantages cited were that the tests missed small deficits $(N=5)$, the norms did not always correspond to the children being tested ( $N=15)$, and many tests were not available to the clinicians or were too expensive to purchase $(\mathrm{N}=60)$.

Results of normed instruments were described by 13 clinicians as helping to regulate their caseloads by only allowing the most severe children onto their schedules. Twenty-six respondents, however, complained that the use of some instruments resulted in scores that prevented treatment for border-line children that the clinicians and classroom teachers felt needed some extra help.

The expense of test instruments was mentioned along with complaints of budget restraints by over $60 \%(\mathrm{~N}=80)$ of the respondents. Some clinicians cope with the lack of instruments by sharing with other clinicians in their district $(\mathrm{N}=35)$, some paid for many new tests themselves $(\mathrm{N}=30)$, and many respondents made do with first edition versions of tests that had often been revised not only once but two and three times $(\mathrm{N}=45)$. It should be noted that 12 clinicians reported being able to purchase whatever they needed to perform appropriate assessment.

In addition to budget cuts and restraints, written remarks addressed time limitations as well. Time constraints limit language sampling and analysis or any 
other assessment beyond the essential testing for qualification for placement according to $40 \%$ of those making written comments. Additionally, 18 respondents indicated time limits prevented them from reading research and 6 more respondents added to the above fact they did not have the time to try out new test instruments as well. According to 8 clinicians, they did make time for adequate assessment, but at the expense of treatment time or working overtime. It was noted that the above 8 clinicians did not include the 6 respondents that worked in an assessment environment only, who all reported having enough time. As a result of the tightening budget restraints, eligibility qualifications, time restraints, and poor working conditions, there were four survey respondents who reported that they would be leaving this profession within the next 2-3 years.

Despite intensive information regarding the strengths and weaknesses of various assessment methods which had been published, it was not known what methods were actually in use for this state. It was believed that by asking the public school clinicians what assessment methods were currently being practiced, a more accurate impression of what was actually happening in the area of language assessment could be provided. Because the respondents to this survey reported that their methods change over time, it was believed that the data provided by this research represented the most accurate data on the most effective assessment methods presently used in the State of Oregon.

In summary, there were many issues that determined which methods of language assessment were used by speech-language pathologists in the public school setting. Most clinicians relied more on their own judgement as they gained more experience. The most important features in using a test appeared to be: familiarity with the test, availability of the test, scheduled time for testing, and caseload size. Written statements showed that many clinicians also used 
language sampling with a criteria-referenced test for evaluation procedures.

Finding new assessment tools was mainly determined by word of mouth from other clinicians and workshops that clinicians attend. Overall, the survey respondents had become very adept at taking information that they currently used and adding it to new information that they found both useful and timeefficent. 


\section{CHAPTER V}

\section{SUMMARY AND IMPLICATIONS}

\section{Summary}

Every student who receives speech and language services in the public school system must first qualify for services by showing need on at least one standardized test. Heward \& Orlansky, 1992, state that placement must not be made on the basis of one test alone. Much advice has been published in the last 40 years in an attempt to aid speech-language pathologists in which assessment tools to choose (e.g. Danwitz, 1981; Darley, 1979; Launer \& Lahey, 1981). With so many tests on the market, questions have arisen on what tests are actually being used in the public school systems in various states and what are some reasons for those tests use over other tests. This study was developed to determine what methods of assessment of children's language were currently used by speech-language pathologists working in Oregon public schools. The data bank of information was very low in this area as only one other study, Wilson, Blackmon, Hall, \& Elcholtz, 1991, had done a survey of a state to determine what was currently being used in the area of language assessment.

The primary research question to be answered was: What methods of language assessment were being used in Oregon? Secondary questions to be answered were: (a) What factors influence the selection and use of the chosen procedures?, (b) What are the dates of development of the tests used most frequently, (c) By what means do the public school clinicians keep themselves current with new trends and information in the field? 
A list of 567 public-school speech-language pathologists was compiled from the 1992 directory of the Oregon Speech-Language-Hearing Association and the 1992-1993 Directory of Oregon Public Schools. Each subject was mailed an anonymous survey with a return envelope and asked to fill out questions pertaining to use of formal-published tests, language sampling and other methods of assessment. A series of forced choice questions were developed to determine what factors influence the respondents' selection of assessment materials.

Of the 297 respondees, only 4 reported not using any formal instruments to do language assessment. Results showed that for measuring expressive language 9 main standardized tests were used by the majority of the respondents. Here they are listed in order of frequency of use: TOLD; EOWPVT; WORD test; CELF; LPT; SPELT; ASSET; TOPS; and the PLS. For receptive language the 10 main tests were as follows: PPVT; TOLD; CELF; TACL; ASSET; BOEHM; PLS; ROWPVT; BRACKEN; and the LPT. For complete lists please see Appendices $C$ - F. Some respondents, $n=280$, reported using language sampling in their assessment procedures. Out of these 272 reported using various formal and informal means of transcribing the sample. Factors that influenced the selection and use of specific formal tests included: Personal experience; ease of administration; time restraints; budgets and availability of tests and district protocols for assessments. At the time of this study dates of publication for both the expressive and receptive tests ranged from 1983 - 1990, this included the dates that tests had been revised. At the time of this survey the main ways that clinicians were keeping themselves current for new tests on the market were: Word of mouth from associates, going to inservices on new tests, and by reading new information in journals. 


\section{Implications}

\section{Clinical Implications}

Information gathered from this study provided data that were not available in the current literature for the state of Oregon. In comparing the results to the California study appears that the formal tests used in these two states were similar but not identical; therefore, this concluded that other states may find similar results.

The information found in this study may be useful in Speech-Language Pathology education programs. Here students in preparation for this profession could use these data to become familiar with the tests that they may encounter more frequently than other tests used in the public school setting. This may be especially heipful when the education program targets the preschool population. It will give them the opportunity to look at and practice these tests before going out into the field.

This information could also be helpful for school districts in terms of having in-services for their speech-language pathologists. It could be of help to school districts to provide their clinicians with an annual in-service on new testing procedures each year. Also these findings could be shared with school districts to show what the majority of clinicians were using to assess language in the State of Oregon at the current time and compare what they were using to these findings.

Clinicians could also use these data to learn from each other. The list could be shared within a district so that if one clinician knew how to give one test, they could share their knowledge with another who did not know how to give it. 
The Oregon Department of Education could also use these results as guidelines when developing technical assistance papers for this profession.

The State of Oregon does not currently mandate tests that speechlanguage pathologists are required to use, but it could help consolidate all of the out-dated and infrequently used tests currently being used. Some school districts have gone to mandated tests for their clinicians to use for assessing language.

The information provided in this study was unique in that the methods of public school speech-language pathologists were surveyed. It was believed that, by determining what methods of language assessment were actually in use, a more accurate representation of what constituted effective assessment was achieved. This information may be interpreted to be that which was in practical use in the field for the state of Oregon, regardless of which methods were recommended by current research.

Research Implications

This method of gathering data could be expanded to other age groups, different disorders, and other geographical groups currently providing speech and language services. As more information is gathered and combined with the information found in this study and the Wilson et al. (1991) study, more precision in determining the actual practices of speech-language pathologists will result.

Due to the expense involved in mailing the surveys, this study was limited to the state of Oregon. While the sample is considered of sufficient size to be a representative sample of this state, the results may not be accurately applied to other states due to different University education programs, different qualification standards, and possibly differing educational budgets and other constraints. It is suggested that this study be repeated in other states in order to obtain a good representation of the assessment methods around the country. 
With the passage of PL 99-457 (1986) and IDEA it would be of interest to apply this research to populations of various ages, such as services to infants and preschoolers, high schoolers, and the post-high school age. It would be interesting to see what instruments are used to first identify the preschooler for services, assess them as they develop and move on to high-school, and finally, what tests are used to transition them to the adult service realm, if they are still identified as speech/anguage at that point in life.

While the original questions of this study have been answered, it would be interesting to examine the mean number of years of service of clinicians in the field with the specific tests they use. A comparison of those using newer and older instruments may reveal an interesting correlation between years in the field and test instrument use.

Although the assessment of children in languages other than English was beyond the scope of this study, it would be interesting to know which language tests are being used for non-English speakers. No single instrument for a child speaking a language other than English was mentioned by any of the respondents, although 4 people included in their written responses that they wished that they had second language tests available to them. 


\section{References}

Abraham, S., \& Stoker, R. (1988). Language assessment of hearingimpaired children and youth: Patterns of test use. Language, Speech, and Hearing Services in Schools, 19, 160-174.

Arwood, E. (1985). Arwood pragmaticism institute for communication therapy. Portland, OR: APRICOT, Inc.

Bankson, N.W. (1977). Bankson language screening test. Baltimore, MD: University Park Press.

Barrett, M., Zachman, L., \& Huisingh, R. (1990). Assessing semantic skills through everyday themes. East Moline, III. LinguiSystems.

Berry, M.F. (1980). Teaching linguistically handicapped children. Englewood Cliffs, NJ: Prentice-Hall.

Bloom, L., \& Lahey, M. (1978). Language development and language disorders. New York: John Wiley \& Sons.

Boehm, A. (1969). Boehm test of basic concepts. San Antonio, Texas: The Psychological Corporation, Harcourt-Brace-Jovanovich, Inc.

Bracken, B. (1984). Bracken basic concepts scale. San Antonio, Texas: The Psychological Corporation, Harcourt-Brace-Jovanovich, Inc.

Brown, R. (1973) . A first language. Cambridge, MA: Harvard University Press.

Carrow, E. (1973). The test of auditory comprehension of language. (5th Ed.). Hingham, MA: Teaching Resources Corp.

Carrow, E. (1974). Carrow elicited language inventory. Boston, MA: Teaching Resources Corp.

Carrow-Woolfolk, E., \& Lynch, J.I. (1982). An integrative approach to language disorders in children. New York: Grune \& Stratton.

Danwitz, M.W. (1981). Formal versus informal assessment: Fragmentation versus holism. Topics in Lanquage Disorders, 1, 95-106.

Darley, F.L. (Ed.). (1979). Evaluation of appraisal techniques in speech and language pathology. Massachussetts: Addison-Wesley Publish. Co.

DiSimoni, F. (1978). Token test for children. Allen Texas: DLM Teaching Resources. 
Dunn, L. \& Dunn, L. (1981). Peabody Picture Vocabulary Test. ( rev. ed.) Circle Pines, MN: Academic Guidance Service.

Foster, C.R., Giddan, J.J., \& Stark, J. ( 1969; 1973). Assessment of children's language comprehension. Palo Alto, CA: Consulting Psy. Press.

Gardner, M.F. (1979). Expressive one-word picture vocabulary test. Novato, CA: Academic Therapy Publications.

Gardner, M.F. (1985). Receptive one-word picture vocabulary test. Novato, CA: Academic Therapy Publications.

Goh, D.S., Tesiow, C.J., \& Fuller, G.B. (1981). The practice of psychological assessment among school psychologists. Professional Psychology, 12(6), 696-706.

Hammill, D. (1987). Detroit tests of learning aptitude. Austin, Texas: PRO-ED

Hammill, D.D., \& Newcomer, P.L. (1982). The Test of Language Development-Primary. Austin, TX: Pro-Ed.

Heward, W.L., \& Orlansky, M.D. (1992). Exceptional Children, 4th, Edition. New York: Merrill, MacMillan Publishing Co.

Jorgensen, C., Barrett, M., Huisingh, R., \& Zachman, L. (1981). The WORD test East Moline, III. LinguiSystems.

Kamhi, A.G. (1984). Problem solving in child language disorders: The clinician as clinical scientist. Language, Speech, and Hearing Services in the Schools, 15, 226-234.

Kirk, S.A., McCarthy, J.J, \& Kirk, W.D. (1968). The lllinois Test of Psycholinguistic Abilities. Urbana, IL. University of Illinois Press.

Lass, N.J. (Ed.). (1982). Speech and language: Advances in basic research and practice (Vol. 7). New York: Academic Press.

Launer, P.B., \& Lahey, M. (1981). Passeges: From the fifties to the eighties in language assessment. Topics in Lanuage Disorders, $1(3), 11-29$.

Lee, L.L. (1974). Developmental sentence analysis. Evanston, IL: Northwestern University Press.

Lund, N.J., \& Duchan, J.F. (1983). Assessing children's language in naturalistic contexts. Englewood Cliffs, NJ: Prentice Hall. 
McCarthy, D. (1954). Language development in children. In L. Carmichael (Ed.), Manual of child psychology pp.492-630. New York: John Wiley and Sons.

Meitus, I.J. (1983). Approaching the diagnostic process. In I.J. Meitus \& B. Weinberg (Eds.), Diagnosis in speech-language pathology (pp. 1-30). Baltimore, MD: University Park Press.

Miller, J. F. (1981). Assessing Language Production in Children. Austin, TX: PRO-ED.

Miller, J.F. \& Chapman R. (1993). SALT: Systematic Analysis of Language Transcripts [ Computer programs to analyse language samples.] Madison, WI: Language Analysis Labratory, Waisman Center, University of Wisconsin-Madison.

Muma, J., Pierce, S., \& Muma, D. (1983). Language training in speechlanguage pathology: Substantive domains. ASHA, 25, 35-40.

Muma, J., Webb, P., \& Muma, D. (1979). Language training in speechlanguage pathology and audiology: A survey. ASHA 21, 467-473.

Oregon, State of. (1993) Oregon administrative rules: Eligibility for speech and language requirements. Oregon Department of Education, Salem, Oregon.

Pickett, J.M., \& Flynn, P.T. (1983). Language assessment tool for mentally retarded adults: A survey and recommendations. Mental Retardation, 21 (6), 244-247.

Richard, G., \& Haner, M. (1985). Lanquage Processing Test. East Moline, Illinois: LinguiSystems.

Scarborough, H. (1990). Index of productive syntax.

Applied Psycholinguistics, 11, 1-22.

Semel, E., \& Wiig, E. (1980). Clinical Evaluation of Lanquage Functions. Columbus, $\mathrm{OH}$ : Charles E. Merrill.

Shipley, T., Stone, T., \& Sue, M. (1983). Test for examining expressive morphology. Tucson, AZ: Communication Skill Builders.

Tyack, D. \& Gottsleben, R. (1977). Language sampling, analysis, and training. Palo Alto, CA: Consulting Pyschologists Press.

Werner, E. \& Krescheck, J. (1983). Structured photographic expressive language test. Janelle Publications. 
Wilson, K.S., Blackmon, R.C., Hall, R.E., \& Elcholtz, G.E. (1991).

Methods of language assessment: A survey of california public school clinicians. Language, Speech, and Hearing in Schools, 22, 236-241.

Wilson, K.S. Personal Communication on March 12, 1992.

Zachman, L., Jorgensen, C., Huisingh, R., \& Barrett, M. (1984).

Test of Problem Solving. East Moline, linnois: LinguiSystems.

Zimmerman, I., Steiner, V., \& Pond, R. (1979). Preschool Language Scale.

Columbus, $\mathrm{OH}$ : Charles E. Merrill Publishing Co. 
APPENDIX A 
Please answer the following questions if you are a public school or educational service district clinician working with language disordered children ages 4 to 9 years

How many years have you been assessing and/or providing remediation for this population ?

\section{EXPRESSIVE LANGUAGE}

Please indicate which of the following you use when assessing expressive language ( Please check all that apply):

Published, formal standardized tests

Clinician-devised informal test

Other :

If you indicated that you use published tests to asses expressive language, please list the five that are most commonly used, in order of frequency:

1.
2.
3
5

Do you aquire a language sample? If yes, percentage of the time

\section{RECEPTIVE LANGUAGE}

Which of the following do you use when assessing receptive language?

(Please check all that apply)

Published, formal standardized test

Clinician-devised informal test

Other:

If you indicated that you use published tests to assess receptive language, please list the five that are most commonly used, in order of frequency:

1.

2.

3.

4.

5. 


\section{THE FOLLOWING QUESTIONS PERTAIN TO BOTH EXPRESSIVE AND RECEPTIVE}

\section{LANGUAGE Read all questions before answering.}

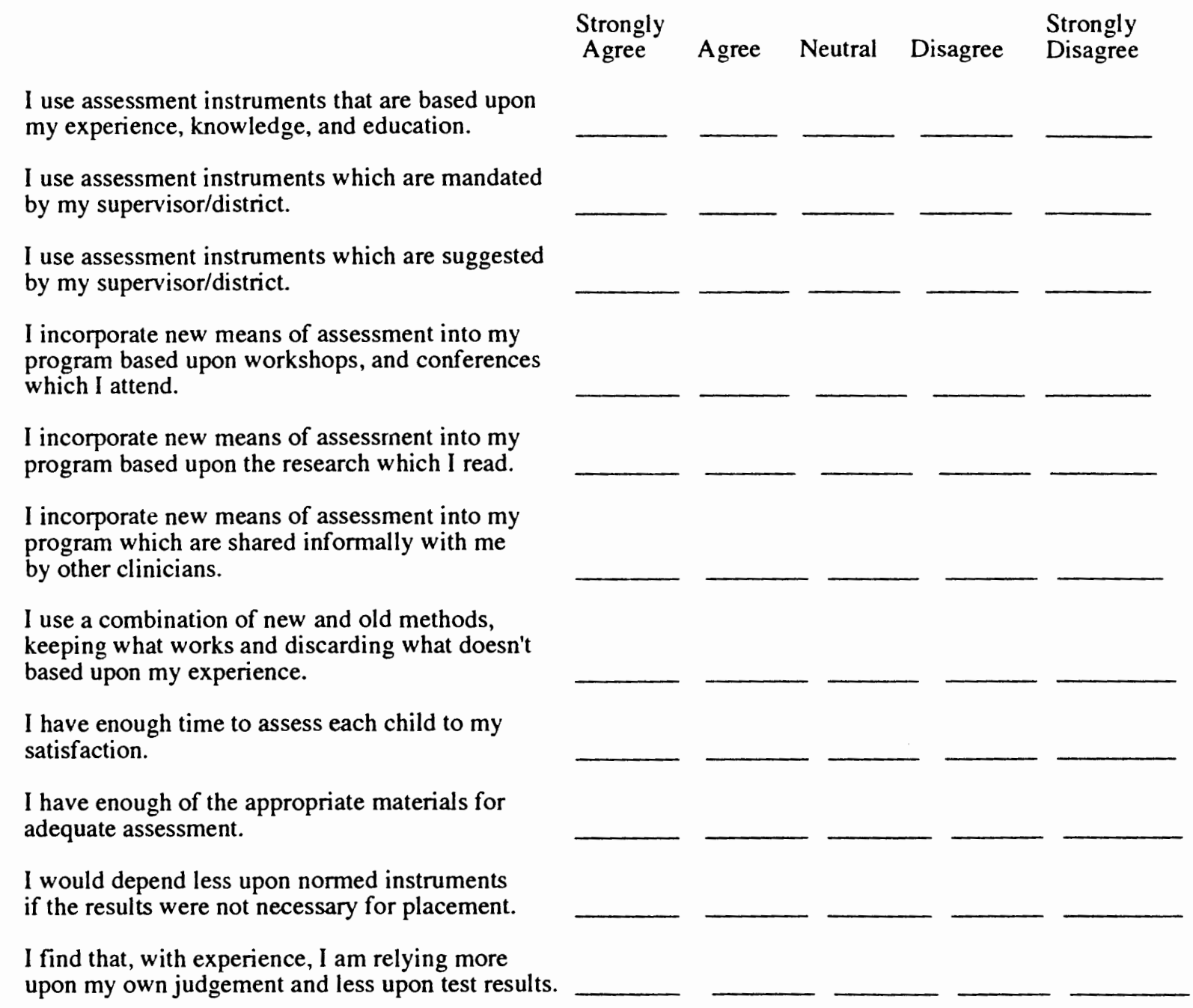

Do you only use the language sample informaily for treatment purposes or do you formally transcribe the language sample?

If you formally transcribe, what method do you use for analysis (e.g. DSS, ASS, IPSYN, MLU)?

Additional comments are welcome ( on the back or attached). 
APPENDIX B 
March 25, 1993

Dear Speech-Language Pathologist,

We are conducting a survey, of public school clinicians in Oregon to determine which language assessment instruments and methods are currently in use. We anticipate completing the study by June, 1993.

As indicated on the top of the attached questionnaire, the survey is directed to public school clinicians who work with language-disordered children ages 4-9 years. Your name was selected from the current directories published by OSHA, the State Licensure Board, or the State Department of Education, which are not specific enough to assure that this letter is mailed only to the population described.

We are hoping that this survey 1) arrives in the appropriate hands and 2) is mailed at a time when it won't be lost in the paperwork of your caseload.

The number of surveys mailed out is limited, and every response is important. If you are not a clinician working with the described population, please pass this brief survey form along to someone who is. If necessary, please feel free to make copies and distribute them, if you know of someone who did not receive a survey.

As a "thank-you" for you participation, we will mail a review of the results to you after compiling the data. If you are interested in receiving this, enclose a selfaddressed envelope when returning the survey. We also hope to have the results published after the study has been completed. All responses will be kept confidential as we request that you not include your name on the returned survey.

The questionnaire is two pages in length, and will require approximately five minutes of your time to complete. A pre-addressed and stamped envelope is enclosed in which to return the form.

Your time is greatly appreciated. Thank you for your assistance. We hope that you can send this survey back in the enclosed envelope by MAY 1, 1993.

Staci Johnson Ball, BS

Portland State University

Master's Candidate

Speech and Hearing Sciences
Joan MCMahon, MS CCC-SLP

Portland State University

Associate Professor

Speech and Hearing Sciences 
APPENDIX C 
RANKED EXPRESSIVE TESTS

TEST

FMS

FMS rank

WUS

WUS rank

\begin{tabular}{lllll} 
TOLD & 211 & 1 & 826 & 1 \\
EOWPVT & 179 & 2 & 632 & 2 \\
WORD TEST & 140 & 3 & 407 & 4 \\
CELF & 127 & 4 & 458 & 3 \\
LPT & 113 & 5 & 338 & 5 \\
SPELT & 94 & 6 & 263 & 7 \\
ASSET & 93 & 7 & 303 & 6 \\
TOPS & 72 & 8 & 161 & 9 \\
PLS & 49 & 9 & 172 & 8 \\
TEEM & 18 & 10 & 47 & 10 \\
SICD & 13 & 11 & 43 & 11 \\
TLC & 11 & 12 & 30 & 13 \\
TOLD-1 & 11 & 13 & 35 & 12 \\
BANKSON & 10 & 14 & 28 & 14 \\
CELF Preschool & 9 & 15 & 27 & 15 \\
PAT & 8 & 16 & 24 & 16 \\
TELD & 7 & 17 & 23 & 17 \\
Test of Word Know. & 6 & 18 & 15 & 21 \\
REEL & 6 & 19 & 18 & 19 \\
TACL & 6 & 20 & 19 & 18 \\
\hline
\end{tabular}




ITPA
DTLA
AAPS
PEST
TOAL
PPVT

Hodson's APP-R 3

Test of Word Find. 3

NSST 3

PLAI 3

CELI 3

Goldman-Fristoe 3

TEMPRO 3

UTAH 3

Woodcock Lng. Pro 3

BRACKEN

5

21

12

24

522

11

25

5

23

4

24

11

27

$4 \quad 25$

10

29

426

14

22

17

20

27

28

6

34

11

26

29

31

30

32

31

32

33

33

34

35

36

38

CADET

2

37

Word Test Adol. 2

38

28

11

30

9

23

13

5

36

5

37

BOEHM

2

Clark-Madison

2

Salem Lang. Screen 2

Story Assessment 1

DIAL SCREEN 1

MILI

1

JOLIET

1

BATTELLE

1

39

46

49

40

35

41

41

42

55

43

47

44

56

45

46

3

1

2

50

5

39 


$\begin{array}{lllll}\text { STAL } & 1 & 47 & 4 & 42 \\ \text { TYACK } & 1 & 48 & 1 & 57 \\ \text { Test of Adol. Lang. } & 1 & 49 & 5 & 40 \\ \text { PALST } & 1 & 50 & 4 & 43 \\ \text { TAPS } & 1 & 51 & 2 & 51 \\ \text { MAP } & 1 & 52 & 2 & 52 \\ \text { MCDonald Deep } & 1 & 53 & 2 & 53 \\ \text { ROSSETTI } & 1 & 54 & 4 & 44 \\ \text { Wepman Aud. Dis. } & 1 & 55 & 3 & 48 \\ \text { TOWL } & 1 & 56 & 2 & 54 \\ \text { WEISS } & 1 & 57 & 4 & 45\end{array}$


APPENDIX D 
Expressive Language Assessments Instruments Mentioned by Respondents

\section{Frequency \\ of \\ Mention}

211

Test of Language Development (TOLD) 3rd Ed. (1988).

D. Hammill \& P. Newcomer. PRO-ED.

Expressive One-Word Picture Vocabulary Test (1985).

179

M.F. Gardner. Academic Therapy Publications.

The WORD Test (1981). C. Jorgensen, M. Barrett, R.

Huisingh, \& L. Zachman. LinguiSystems.

Clinical Evaluation of Language Functions (CELF) revised

127

(1987). E.Semel \& E. Wiig. Charles E. Merrill Pub. Co.

Language Processing Test (LPT) (1985). G. Richard \& M.

Hanner. LinguiSystems.

Structured Photographic Expressive Language Test (SPELT)

94

(1983). E. Werner \& J. Krescheck. Janelle Publications.

Assesing Semantic Skills through Everday Themes (ASSET)

93

(1990). M. Barrett, L. Zachman, R. Huisingh. LinguiSystems.

Test of Problem Solving (TOPS) (1984). L. Zachman, C.

72

Jorgensen, R. Huisingh, \& M. Barrett. LinguiSystems.

Preschool Language Scale (PLS) (1979). I. Zimmerman, V.

49

Steiner \& R. Pond. Charles E. Merrill Publishing Co.

Test for Examining Expressive Morphology (TEEM) (1983). K. 18

Shipley, T. Stone, \& M. Sue. Communication Skill Builders. 
Sequenced Inventory of Communication Development (SICD)

(1979). D. Hedrick, E. Prather, \& A. Tobin. Unversity of

Washington Press.

Test of Language Competence (TLC) (1985). E. Wiig \& W.

Secord. The Psychological Corporation. Harcourt-Brace

Test of Lanquage Development-Intermediate (TOLD-I) (1982).

D. Hammill \& P. Newcomer. PRO-ED.

Bankson Lanquage Screening Test (1977). N. Bankson.

University Park Press.

Clinical Evaluation of Language Function - Preschool (1980).

9

E. Semel \& E. Wiig. Charles E. Merrill Publishing Company.

Photo Articiculation Test (PAT) (1969). K. Pendergrast, S.

8

Dickey, J. Selmar, \& A. Soder. Interstate Printers \&

Publishers Incorporated.

Test of Early Language Development (TELD) (1981). W.

Hresko, D.K. Reid, \& D. Hammill. PRO-ED.

Test of Word Knowledge (TOWK) (1991).

E. Wiig \& W. Secord. The Psychological Co. Harcourt-BraceJovanovich, Inc.

Receptive-Expressive Emergent Language Scale (REEL) (1978)

K. Bzoch \& R. League. PRO-ED

Test for Auditory Comprehension of Language (TACL) (1985).

6

E. Carrow-Woolfolk. DLM Teaching Resources.

llinois Test of Pycholinguistic Abilities (ITPA) (1968).

S. Kirk, J. McCarthy, \& W. Kirk. University of Illinois Press. 
Detroit Tests of Learning Aptitude (DTLA) (1987).

D.D. Hammill. PRO-ED.

Arizona Articulation Proficiency Scale (AAPS) (1970).

J. Fudala. Western Psychological Services.

Test of Adolescent Language (TOAL) (1987).

D. Hammill, V. Brown, \& S. Larsen. PRO-ED.

Patterned Elicitation Syntax Test (PEST) (1983).

E. Young \& J. Perachio. Communication Skill Builders.

Peabody Picture Vocabulary Test (PPVT) (1981).

L. Dunn \& L. Dunn. American Guidance Service.

Assessment of Phonological Processess (APP) (1980).

B. Hodson. Interstate Printers \& Publishers.

Test of Word Finding (1988).

D. German. DLM Teaching Resources.

Northwestern Syntax Screening Test (NSST) (1971).

L. Lee. Northwestern University Press.

Preschool Lanquage Assessment Instrument (PLAI) (1978).

M. Blank, S. Rose, \& L. Berlin. Grune \& Stratton, Inc.

Carrow Elicited Language Inventory (CELI) (1974).

E. Carrow. Teaching Resources Corp.

Goldman-Fristoe Test of Articulation - 3rd Ed. (1986).

R. Goldman \& M. Fristoe. American Guidance Service (AGS).

Temporal Analysis of Propositions: A Tool for Analysing Language

Functioning (TEMPRO) (1992).

E. Arwood \& M. Beggs. Apricot, Inc. 
Utah Test of Language Development (UTLD) (1978).

M.J. Mecham \& J. Jones. Communication Research Assoc. Inc.

Woodcock-Language Proficiency Battery (1991).

R.W. Woodcock. DLM.

Bracken Basic Concepts Scale (1984).

B. Bracken. Psychological Corporation.

Communication Abilities Diagnostic Test (CADeT) (1990).

E. Johnston \& A. Johnston. Communication Skill Builders.

The WORD Test-Adolescent (1989).

L. Zachman, R. Huisingh, M. Barrett, J. Orman, \& C. Blagden.

LinguiSystems.

Boehm Test of Basic Concepts (1969).

A. Boehm. Psychological Corporation.

Clark-Madison Test of Oral Language (1986).

J. Clark \& C. Madison. PRO-ED.

Salem School District Language Screen.

Salem School District, Salem, OR.

Story Assessment - Picture Story Language Test. (1965).

H. Myklebust. Grune \& Stratton- New York.

Developmental Indicators of Assessment of Learning (DIAL) (1990).

D. Mardell-Czudnowski \& D. Goldenberg. DIAL, inc.

Multilevel Informal Language Inventory (MILI) (1982).

C. Goldsworthy. Charles E. Merrill Publishing Co.

Joliet 3- Minute Speech \& Language Screen (1983).

M. Kinzler \& C. Johnson. Communication Skill Builders. 
Battelle Developmental inventory (1984).

J. Newborg, J. Stock, L. Wnek, J. Guidubaldi, \& J. Svincki.

DLM Teaching Resources.

Screening Test of Adolescent Language (STAL) (1980).

E.M. Prather, S.V.A. Breecher, M.L. Stafford, \& E.M. Wallace

University of Washington Press.

Language Sampling, Analysis, and Training (TYACK) (1974).

D. Tyack \& R. Gottsleben. Consulting Psychologists Press, Inc.

Picture Articulation \& Language Screening Test (PALST) (1976).

W.C. Rodgers. World Making Productions.

Test of Auditory Perceptual Skills (TAPS) (1985).

M. Gardner. Children's Hospital of California.

Muma Assessment Program (MAP) (1979).

J.R. Muma \& D.B. Muma. Natural Child Pub. Co.

McDonald Deep Test of Articulation (1964).

E.T. McDonald. Stanwix House, Inc.

Rossetti Infant-Toddler Language Scale (1990).

L. Rossetti. LinguiSystems, Inc.

Wepman Auditory Discrimination Test (1958).

J. Wepman. Language Research Associates.

Test of Written Language -Revised (TOWL) (1988)

D. Hammill \& S. Larsen. American Guidance Service.

Weiss Comprehensive Articulation Test (1978).

C.E. Weiss. Teaching Resource. 
APPENDIXE 


\begin{tabular}{llll}
\hline TEST & FMS & WMS rank WUS W
\end{tabular}

\begin{tabular}{|c|c|c|c|}
\hline PPVT & 245 & 1 & 998 \\
\hline TOLD & 176 & 2 & 633 \\
\hline CELF & 122 & 3 & 433 \\
\hline TACL & 114 & 4 & 374 \\
\hline ASSET & 89 & 5 & 298 \\
\hline BOEHM & 85 & 6 & 226 \\
\hline PLS & 49 & 7 & 177 \\
\hline ROWPVT & 48 & 8 & 151 \\
\hline BRACKEN & 39 & 9 & 106 \\
\hline LPT & 38 & 10 & 106 \\
\hline Token Test & 23 & 11 & 49 \\
\hline WORD Test & 22 & 12 & 68 \\
\hline $\operatorname{SICD}$ & 13 & 13 & 34 \\
\hline TOPS & 12 & 14 & 20 \\
\hline DTLA & 9 & 15 & 22 \\
\hline CELF Preschool & 8 & 16 & 28 \\
\hline TOLD-I & 8 & 17 & 25 \\
\hline TLC & 7 & 18 & 20 \\
\hline REEL & 7 & 19 & 17 \\
\hline TELD & 6 & 20 & 16 \\
\hline BANKSON & 6 & 21 & 19 \\
\hline Test of Word Know. & 4 & 22 & 10 \\
\hline
\end{tabular}




\begin{tabular}{|c|c|c|c|c|}
\hline EOWPVT & 4 & 23 & 10 & 22 \\
\hline TOAL & 4 & 24 & 10 & 24 \\
\hline NSST & 3 & 25 & 8 & 27 \\
\hline Listening Test & 3 & 26 & 6 & 30 \\
\hline AAPS & 3 & 27 & 7 & 29 \\
\hline ACLC & 3 & 28 & 5 & 32 \\
\hline ITPA & 3 & 29 & 10 & 25 \\
\hline Wepman Aud. Dis. & 3 & 30 & 6 & 31 \\
\hline Lindamood Aud.Con. & 3 & 31 & 5 & 35 \\
\hline CADET & 2 & 32 & 7 & 28 \\
\hline Goldman-Fristoe & 2 & 33 & 9 & 26 \\
\hline SPELT & 2 & 34 & 3 & 42 \\
\hline UTAH & 2 & 35 & 4 & 36 \\
\hline TAPS & 2 & 36 & 4 & 39 \\
\hline CELI & 2 & 37 & 5 & 34 \\
\hline DIAL SCREEN & 1 & 38 & 2 & 44 \\
\hline BATTELLE & 1 & 39 & 5 & 33 \\
\hline WORD Test Adol. & 1 & 40 & 4 & 37 \\
\hline Woodcock-Johnson & 1 & 41 & 3 & 43 \\
\hline STAL & 1 & 42 & 4 & 38 \\
\hline PAT & 1 & 43 & 2 & 45 \\
\hline PALST & 1 & 44 & 4 & 40 \\
\hline MAP & 1 & 45 & 2 & 46 \\
\hline ROSSETTI & 1 & 46 & 4 & 41 \\
\hline Bangs Rec. Voc. List & 1 & 47 & 2 & 47 \\
\hline
\end{tabular}


APPENDIX F 
Receptive Language Assessment Instruments Mentioned by Respondents

Peabody Picture Vocabulary Test (PPVT) (1981).

L. Dunn \& L. Dunn. American Guidance Service.

Test of Language Development (TOLD) (1982).

D. Hammill \& P. Newcomer. PRO-ED.

Clinical Evaluation of Language Functions (CELF) (1980).

E. Semel \& E. Wiig. Charles E. Merrill Publishing Co.

Test for Auditory Comprehension of Language (TACL) (1985).

E. Carrow-Woolfolk. DLM Teaching Resources.

Assesing Semantic Skills through Everday Themes (ASSET)

(1990). M. Barrett, L. Zachman, R. Huisingh. LinguiSystems.

Boehm Test of Basic Concepts (1969).

A. Boehm. Psychological Corporation.

Preschool Language Scale (PLS) (1979). I. Zimmerman, V.

Steiner \& R. Pond. Charles E. Merrill Publishing Co.

Receptive One-Word Picture Vocabulary Test (ROWPVT) (1985)

M. Gardner. Academic Therapy Publications.

Bracken Basic Concepts Scale (BBCS) (1984).

B. Bracken. Psychological Corporation.

Language Processing Test (LPT) (1985). G. Richard \& M.

Hanner. LinguiSystems.

Token Test (1978)

F. DiSimoni. Teaching Resources Corporation.

The WORD Test (1981). C. Jorgensen, M. Barrett, R.

Huisingh, \& L. Zachman. LinguiSystems. 
Sequenced Inventory of Communication Development (SICD)

(1979). D. Hedrick, E. Prather, \& A. Tobin. Unversity of

Washington Press.

Test of Problem Solving (TOPS) (1984). L. Zachman, C.

Jorgensen, R. Huisingh, \& M. Barrett. LinguiSystems.

Detroit Tests of Learning Aptitude (DTLA) (1987).

D.D. Hammill. PRO-ED.

Clinical Evaluation of Language Function Preschool (1980).

E. Semel \& E. Wiig. Charles E. Merrill Publishing Company.

Test of Language Development-Intermediate (TOLD-1) (1982).

D. Hammill \& P. Newcomer. PRO-ED.

Test of Language Competence (TLC) (1985). E. Wiig \& W.

Secord. The Psychological Corporation. Harcourt-Brace.

Receptive-Expressive Emergent Language Scale (REEL) (1978)

K. Bzoch \& R. League. PRO-ED.

Test of Early Language Development (TELD) (1981). W.

Hresko, D.K. Reid, \& D. Hammill. PRO-ED.

Bankson Language Screening Test (1977). N. Bankson.

University Park Press.

Test of Word Knowledge (TOWK) (1991)

E. Wiig \& W. Secord. The Psychological Corp.

Expressive One-Word Picture Vocabulary Test (1985).

M.F. Gardner. Academic Therapy Publications.

Test of Adolescent Language (TOAL) (1987).

D. Hammill, V. Brown, \& S. Larsen. PRO-ED. 
Northwestern Syntax Screening Test (NSST) (1971).

L. Lee. Northwestern University Press.

The Listening Test (1992).

M. Barrett, R. Huisingh, L. Zachman, C. Blagden \& J. Orman.

LinguaSystems.

Arizona Articulation Proficiency Scale (AAPS) (1970).

J. Fudala. Western Psychological Services.

Assessment of Children's Language Comprehension (ACLC) (1973).

R. Foster, J.J. Gidden, J. Stark. Consulting Psychologists Press.

Illinois Test of Pycholinguistic Abilities (ITPA) (1968).

S. Kirk, J. McCarthy, \& W. Kirk. University of lllinois Press.

Wepman Auditory Discrimination Test (1958).

J. Wepman. Language Research Associates.

Lindamood Auditory Concepts Test (1971)

C.H. Lindamood \& P.C. Lindamood. Teaching Resources.

Communication Abilities Diagnostic Test (CADeT) (1990).

E. Johnston \& A. Johnston. Communication Skill Builders.

Goldman-Fristoe Test of Articulation - 3rd Ed. (1986).

R. Goldman \& M. Fristoe. American Guidance Service (AGS).

Structured Photographic Expressive Language Test (SPELT)

(1983). E. Werner \& J. Krescheck. Janelle Publications.

Utah Test of Language Development (UTLD) (1978).

M.J. Mecham \& J. Jones. Communication Research Assoc. Inc.

Test of Auditory Perceptual Skills (TAPS) (1985)

M. Gardner. Children's Hospital of California. 
Carrow Elicited Language Inventory (CELI) (1974).

E. Carrow. Teaching Resources Corp.

Developmental indicators of Assessment of Learning (DIAL) (1990).

D. Mardell-Czudnowski \& D. Goldenberg. DIAL Inc.

Battelle Developmental Inventory (1984).

J. Newborg, J. Stock, L. Wnek, J. Guidubaldi, \& J. Svincki.

DLM Teaching Resources.

The WORD Test-Adolescent (1989).

L. Zachman, R. Huisingh, M. Barrett, J. Orman, \& C. Blagden.

Woodcock-Language Proficiency Battery (1991)

R. W. Woodcock. DLM.

Screening Test of Adolescent Language (STAL) (1980).

E. M. Prather, S.V.A. Breecher, M.L. Stafford, \& E.M. Wallace.

University of Washington Press.

Photo Articiculation Test (PAT) (1969). K. Pendergrast, S.

Dickey, J. Selmar, \& A. Soder. Interstate Printers \&

Publishers Incorporated.

Picture Articulation \& Language Screening Test (PALST) (1976).

W.C. Rodgers. World Making Productions.

Muma Assessment Program (MAP) (1979).

J.R. Muma \& D.B. Muma. Natural Child Pub. Co.

Rossetti Infant-Toddler Language Scale (1990).

L. Rossetti. LinguiSystems, Inc.

The Bangs Receptive Vocabulary Checklist (1990).

T.E. Bangs. Communication Skill Builders. 